\section{O EXAME NACIONAL E DESEMPENHO DOS ESTUDANTES - ENADE - COMO INSTRUMENTO SINALIZADOR PARA AVALIAÇÃO E QUALIFICAÇÃO DE CURSOS PRESENCIAIS DE GRADUAÇÃO EM TURISMO SOB A ÓTICA DE COORDENADORES DE CURSO}

THE NATIONAL STUDENTS PERFORMANCE EXAM - ENADE - AS A SIGNALING INSTRUMENT FOR EVALUATION AND QUALIFICATION OF CLASSROOM COURSES OF UNDERGRADUATE IN TOURISM UNDER THE VISION OF COURSE COORDINATORS

THAYS DE OLIVEIRA MARCELINO'

UNIVERSIDADE FEDERAL RURAL DO RIO DE JANEIRO, NOVA IGUAÇU, RIO DE JANEIRO, BRASIL

MARCIA MARIA CAPPELLANO DOS SANTOS ${ }^{2}$

UNIVERSIDADE DE CAXIAS DO SUL, RIO GRANDE DO SUL, BRASIL

DATA DE SUBMISSÃO: 07/04/2018 -DATA DE ACEITE: 12/03/2019

\begin{abstract}
RESUMO: Este trabalho, de caráter qualitativo e exploratório, objetiva analisar processos de mudança e qualificação, conduzidos por coordenações de curso, de projetos pedagógicos e de práticas pedagógicas e avaliativas resultantes de estudo analítico-interpretativo da prova do Enade para os cursos de graduação em Turismo e do respectivo relatório. Optou-se, como recorte temporal e espacial pela prova de 2012 e por cursos presenciais oferecidos no RS por instituições de diferentes naturezas jurídicas que haviam participado das edições anteriores. Entrevistas semiestruturadas versaram sobre quatro eixos: (a) organização do processo operacional de análise, (b) concepções de turismo subjacentes às questões, (c) avaliação das questões de cunho geral e (d) concepções pedagógicas e metodológicas igualmente subjacentes às questões. As teorias que estariam na base das questões não são explicitadas, mesmo sendo apontados, prioritariamente de modo positivo, alguns elementos/ aspectos conceituais e pragmáticos a elas vinculados. Associado a isso, referentemente às repercussões na avaliação e qualificação dos cursos, os resultados ainda apontam que as análises realizadas e as medidas decorrentes empreendidas não refletem a percepção da potencialidade do Enade como instrumento avaliativo complementar para identificação, compreensão e desenvolvimento de

1 Mestre em Turismo e Hospitalidade pela Universidade de Caxias do Sul, Rio Grande do Sul, Brasil. E-mail: thaysmarcelino@yahoo.com.br. Orcid: https://orcid.org/0000-0001-9282-4768.

2 Doutora em Educação, Universidade Federal de São Carlos, São Paulo, Brasil. E-mail: mcsantos@ucs.br. Orcid: https:// orcid.org/0000-0002-1720-4523
\end{abstract}


Rev.Tur., Visão e Ação, v21, n2, p68-81, Mai./Ago. 2019 - Balneário Camboriú, Santa Catarina, Brasil

PALAVRAS-CHAVE: Graduação em Turismo. Enade. Repercussões institucionais e pedagógicas.

\begin{abstract}
This qualitative and exploratory study aims to analyze processes of change and qualification led by the coordinators of pedagogical projects, and the pedagogical and evaluative practices resulting from an analytical-interpretative study of the Enade exam for undergraduate courses in Tourism and its respective report. The temporal and special cut-offs chosen were the 2012 exam, and the presential courses offered in the state of Rio Grande do Sul by different types of institutions that had participated in the previous editions. The semi-structured interviews focused on four axes: (a) organization of the operational process of analysis, (b) conceptions of tourism underlying the issues, (c) evaluation of general issues and (d) pedagogical and methodological conceptions also underlying the issues. The theories that form the basis of the issues are not explicit, even though some conceptual and pragmatic aspects/elements linked to those issues are pointed out, mostly in a positive way. Related to this, in relation to the repercussions on the evaluation and qualification of the courses, the results still indicate that the analyses conducted, and the measures taken, do not reflect the perception of the potential of the Enade as a complementary instrument of assessment for the identification, understanding, and development of cognitive and metacognitive operations that are relevant to the development of the appropriate skills for the process of training tourism professionals.
\end{abstract}

KEYWORDS: Undergraduate course in Tourism. Enade. Institutional and pedagogical repercussions.

RESUMEN: Este trabajo, de carácter cualitativo y exploratorio, objetiva analizar procesos de cambios y calificación, conducidos por coordinaciones de carrera, de proyectos pedagógicos y de prácticas pedagógicas y evaluativas resultantes del estudio analítico-interpretativo de la prueba del Examen Nacional de la Enseñanza Secundaria (ENADE) para las carreras de grado en Turismo y del respectivo informe. Se ha optado, como recorte temporal y espacial por el examen del 2012 y por las carreras presenciales ofrecidas en la provincia de Rio Grande do Sul por instituciones de diferentes naturalezas jurídicas que habían participado en las ediciones anteriores. Entrevistas semiestructuradas versaron sobre cuatro ejes: (a) organización del proceso operacional de análisis, (b) concepciones de turismo subyacentes a las cuestiones, (c) evaluación de las cuestiones de cuño general y (d) concepciones pedagógicas y metodológicas igualmente subyacentes a las cuestiones. A las teorías que estarían en la base de las cuestiones no son explicitadas, aunque sean señaladas, prioritariamente de modo positivo, algunos elementos/aspectos conceptuales y pragmáticos a ellas vinculados. Asociado a eso, referentemente a las repercusiones en la evaluación y calificación de las carreras, los resultados aún conllevan a los análisis realizados y a las medidas decurrentes emprendidas no refleten la percepción de la potencialidad del Enade como instrumento evaluativo complementar para la identificación, comprensión y desarrollo de operaciones cognitivas y metacognitivas, a su vez, relevantes al desarrollo de las competencias propias al proceso de formación del licenciado en Turismo.

PALABRAS-CHAVE: Licenciado en Turismo. Enade. Repercusiones institucionales y pedagógicas.

\title{
INTRODUÇÃO
}

Pensar em avaliação implica pensar em mudanças, pois a utilização dessa ferramenta na estrutura educacional pode proporcionar questionamentos que podem resultar em reajustes e melhorias para a qualidade na educação. Avaliar é colocar em reflexão/teste/experimento procedimentos de ensino e aprendizagem e, assim, provocar novas percepções, despertar para projeção de mudanças. 
Inserida no complexo educacional-pedagógico, a avaliação nunca será um fim em si mesma. Ela é parte integrante do sistema educacional, possuindo diversas variáveis que a condicionam e é, também, um desdobramento de procedimentos administrativos, atingindo a esfera social e a responsabilidade educacional de um país.

A presente pesquisa situa a avaliação no âmbito acadêmico, ou, em outras palavras, naquele que se processa nas universidades ou em instituições de diferentes perfis organizacionais a quem legalmente foi concedida essa prerrogativa (neste trabalho, subsumidos ao termo "Universidade").

É sabido que cada instituição de ensino desenvolve uma concepção de formação que reflete uma concepção de educação. Isso repercute no posicionamento institucional, abrangendo desde sua missão e princípios, até suas diretrizes de ação, num conjunto de elementos que norteiam a proposição do projeto pedagógico institucional, dos projetos pedagógicos de curso (com seus referenciais ético-sociais, epistemológicos, científicotécnicos, psicopedagógicos, entre outros); a ação do corpo docente junto aos alunos, como também do corpo administrativo que dá suporte à efetivação das atividades acadêmicas. Assim sendo, a avaliação, decorrente de processos externos ou internos, no âmbito institucional ou da sala de aula, reflete os modelos de educação estabelecidos.

Em se tratando da educação superior, esses modelos, no entanto, como observa Goergen (1997) - e neles, também a concepção de avaliação -, refletem ainda traços da concepção de universidade que a instituição, ou os órgãos educacionais em âmbito nacional, estadual, ou mesmo local, assumem. Antecedendo às questões de operacionalidade, o que está em jogo, ao falar e pensar a avaliação na e para a Universidade, é mais do que apenas performance; está em jogo sua razão de ser.

Nesse contexto ou diante dele, caberia aqui ressaltar a importância que o tema "avaliação" foi ganhando - e deverá continuar a ganhar - no Brasil, no que diz respeito às suas repercussões educacionais, sociais e políticas, considerando que a sociedade caminha de forma gradual para o entendimento da relevância da educação de qualidade, o que consequentemente levará à cobrança por resultados indicativos de qualificação crescente. Historicamente, em diferentes níveis e instâncias administrativas, implantaramse programas avaliativos, dentre os quais se encontra o Programa de Avaliação Institucional das Universidades Brasileiras - PAIUB, implementado em 1993, e o Exame Nacional dos Cursos - o Provão, criado em 1996 (Reis, 2011). A este sucedeu, em 2004, a nova proposta de avaliação, classificação e qualificação do sistema superior brasileiro, o Sistema Nacional de Avaliação da Educação Superior (SINAES). Esse sistema desenvolve um processo de avaliação por meio da complementaridade de instrumentos, sob a responsabilidade de diferentes órgãos, que possibilitam a obtenção de informações sobre a qualidade da educação superior, bem como sobre a situação das instituições e dos cursos que ofertam (BRASIL, 2004). Entre esses instrumentos está o Exame Nacional do Desempenho dos Estudantes - Enade.

O Art. $5^{\circ}$ da Lei n. 10.861 , em seu parágrafo $1^{\circ}$ assim dispõe:

$\S 1^{\circ}$ - O Enade aferirá o desempenho dos estudantes em relação aos conteúdos programáticos previstos nas diretrizes curriculares do respectivo curso de graduação, suas habilidades para ajustamento às exigências decorrentes da evolução do conhecimento e suas competências para compreender temas exteriores ao âmbito específico de sua profissão, ligados à realidade brasileira e mundial e a outras áreas do conhecimento. 
Nesse contexto, há que se ter presente que dois universos se põem em relação quando se entrecruzam concepções e práticas das avaliações externa (exames de âmbito local, estadual, nacional, por exemplo) e interna, esta pautada por referentes pedagógicos teórico-práticos que embasam as atividades desenvolvidas cotidianamente em sala de aula nas diferentes instituições de educação superior (IES). E como não poderia ser diferente, esse cenário suscita questionamentos em diferentes espaços e níveis educacionais: Como se dá o processo de retroalimentação entre esses universos? Como dimensionar o papel formativo que deveria predominantemente sustentar as práticas avaliativas (externa e interna), em detrimento da priorização da função regulatória? Como redimensionar a qualidade de projetos, processos e ações em ambos os universos (externo e interno) na perspectiva de promover contínuas melhorias? Trata-se de questões que necessitam ser postas para não haver cristalizações, conclusões simplistas e redutoras, sem o devido olhar analítico.

Entende-se que esses questionamentos, por sua relevância, devam se estender também ao âmbito do Exame Nacional de Desempenho de Estudantes - Enade - no presente estudo, relativo à prova de 2012 para os cursos de graduação em Turismo. A primeira prova destinada aos cursos de graduação em Turismo foi em 2006. Segundo o relatório gerado pelo Instituto Nacional de Estudos e Pesquisas Educacionais Anísio Teixeira - INEP, foram avaliados 397 cursos naquele ano. A segunda aplicação da prova ocorreu em 2009, contando com a participação de 316 cursos no país. Já a terceira edição, no ano de 2012, o número de cursos avaliados reduziu-se a 174. Não se dispunha ainda, quando da realização da pesquisa, do relatório referente à prova de 2015, logo, não se tinha conhecimento do número de cursos que foram avaliados naquele ano.

Os cursos superiores de Turismo já apresentam uma caminhada de mais de 40 anos no país, abrangendo um período marcado por significativas mudanças sociais, políticas, legais e culturais. Do ponto de vista científico, o turismo vem sendo analisado desde perspectivas teóricas de cunho predominantemente econômico-comercial, até aquelas em que se atribui ao caráter humano ou humano-social o cerne do fenômeno turístico, mediante abordagens analíticas como a fenomenológica, a sociológica, a psicológica, entre outras como será abordado panoramicamente no próximo item. É, pois, de supor que reflexos da dinâmica das construções teóricas já comecem a fazer sentir-se no âmbito da graduação, provavelmente com a tendência de se tornarem crescentemente efetivos.

Novas perspectivas teóricas também foram sendo construídas no âmbito pedagógico, tendo em conta inter-relações estabelecidas, por exemplo, com os domínios social, epistemológico e psicológico. Em consequência disso, também é de supor que diferentes processos avaliativos venham a agregar-se aos tradicionais e tendam a ganhar espaço no ensino do Turismo, desafiando a que se promovam novas/outras práticas pedagógicas no âmbito da sala de aula, bem como no de políticas públicas educacionais e institucionais.

Face à amplitude e à complexidade desse cenário, não se pode dar por esgotadas reflexões, ações e correções já efetivadas em âmbitos diversos e por diferentes agentes na busca de qualificação permanente dos cursos de graduação e, no presente contexto, dos cursos de graduação em Turismo. Coordenadores, docentes e alunos dispõem de dados/ resultados do Enade já socializados, mas cuja análise interpretativa poderá sempre ser enriquecida sob outros olhares. Nesse sentido, este estudo intenta não ficar à margem dessa possibilidade. Aqui se insere, pois, a questão de pesquisa a que se busca responder: 
Tendo presente questões de cunho geral e específico que compõem a prova do Enade - no presente estudo, aplicada a cursos de graduação em Turismo -, bem como o respectivo relatório disponibilizado a cada edição da prova, como se configura o processo analítico desses documentos conduzido por coordenações de cursos e que repercussões nos projetos e nas práticas pedagógicas se identificam advindas das análises realizadas?

Especificamente, o estudo busca identificar e analisar: (a) como o curso se organiza para o processo de análise da prova e do relatório no que diz respeito às instâncias envolvidas; (b) como são percebidas/avaliadas as questões de formação geral; (c) como é percebido/ avaliado o enfoque dado com relação a concepções do Turismo subjacentes às questões da prova; (d) como são percebidas concepções de ordem pedagógico-metodológica subjacentes às questões formuladas; (e) que repercussões advieram da análise da prova na avaliação de desempenho dos alunos, na reavaliação do projeto pedagógico do curso e nas decorrentes práticas pedagógicas.

Conforme a revisão de literatura realizada, embora tenham sido localizados alguns trabalhos que versam sobre o Enade ou sobre o Enade/Turismo, não foram encontradas pesquisas com foco dentro do escopo desta investigação, ou seja, a repercussão do Enade na qualificação dos cursos de Turismo em termos de melhorias no Projeto Pedagógico e nas práticas pedagógicas avaliativas, sob a ótica das coordenações de curso. Foram feitas incursões no Banco de Teses e Dissertações da Capes, no repositório de dissertações e teses dos programas de pós-graduação em Turismo e Hospitalidade, no Portal de Periódicos Capes, nos periódicos abrigados pelos cursos de pós-graduação em Turismo e Hospitalidade, em anais do Seminário de Pesquisa em Turismo do Mercosul e da Associação Nacional de Pesquisa e Pós-Graduação em Turismo. Esses dados vêm adensar a relevância científica e social da presente pesquisa.

\section{QUADRO PANORÂMICO DE SUPOSTOS TEÓRICOS DE REFERÊNCIA}

Consideradas influências e relações exercidas pelo turismo em diferentes contextos sociais e o papel da Academia na sistematização e na produção do conhecimento na área, mostra-se pertinente, para construir parte de um marco teórico neste trabalho, revisitar, ainda que apenas panoramicamente, formulações conceituais de turismo construídas em diferentes momentos, com aspectos convergentes e/ou divergentes, os quais possibilitaram diferentes tempos e espaços de interlocução entre elas.

Para tanto, serão tomadas particularmente como referente, por suas propostas e presença acadêmica, as obras Filosofia do Turismo: teoria e epistemologia, de Alexandre Panosso Netto (2011) e Turismo: perspectiva crítica - textos reunidos, de Alexandre Panosso Netto e Marcelino Castillo Nechar (2016).

Duas vertentes marcaram as produções iniciais em Turismo: a econômica e a social, as quais foram consideradas como indissociáveis na concepção de Hunziker e Krapf (1942), passando o turismo a ser visto como um fenômeno socioeconômico. Também por décadas, pesquisadores definiram o turismo à luz de sua formação acadêmica de origem, dando ao fenômeno diversas interpretações: geográfica, matemática, sociológica, filosófica, entre outras aproximações teóricas (Panosso Netto, 2011). 
Na rota de busca de maior compreensão do Turismo, diferentes abordagens foram se constituindo, dentre as quais se encontra a sistêmica, pautada pela Teoria Geral do Sistema abordagem essa associada a uma visão holística e, de certo modo, considerada um paradigma nos estudos turísticos, principalmente na América Latina, como observam Panosso Netto e Nechar (2016). Diacronicamente, são referidos Cuervo (1967) e, juntamente com ele, Wahab (1977), Leiper (1979, 2003), Sessa (1985), Molina (1991), Boullon (2002). No Brasil, destaque especial é dado a Beni (2008), com sua proposição do Sistema de Turismo (Sistur).

Agregando outras dimensões na interpretação do sistema turístico, Panosso Netto (2011) destaca Martinez (2004), para quem o turismo, em sendo uma atividade de pessoas para pessoas, pressupõe essencialmente uma correspondência entre satisfações do turista e da comunidade receptora. Nesse quadro, um lugar particular é dado a Krippendorf (2003), para quem há uma relação entre consciência turística e modo de vida, este englobando diferentes esferas da existência e não apenas a viagem.

Na referência a Sergio Molina (2003), Panosso Netto (2011) destaca o "Pósturismo", discutindo as etapas pelas quais o turismo vem sendo desenvolvido/discutido/ analisado. Igual relevo atribui às plataformas de Jafar Jafari (1994): Defesa, Advertência, Adaptação, do Conhecimento, do Interesse Público, esta proposta em 2005.

Voltando ao Brasil, outras referências vêm somar-se às citadas nas obras de Panosso Netto (2011) e Panosso Netto e Nechar (2016) e a outras ali não mencionadas, às quais estão ligadas às releituras do fenômeno, como o fizeram, entre outros, Moesch (2000, 2013), Gastal e Moesch (2007), Santos Filho (2005), o próprio Panosso Netto (2005, 2011), Perazzolo, Santos e Pereira (2013), Beni e Moesch (2017).

"Campo de práticas histórico-sociais, que pressupõem o deslocamento do(s) sujeito(s), em tempos e espaços produzidos de forma objetiva, possibilitador de afastamentos simbólicos do cotidiano, coberto de subjetividades", assim Moesch (2013, p. 24) define Turismo, sendo esses afastamentos "[...] explicitadores de uma estética diante da busca do prazer, assim denso de invariantes conceituais permitindo um movimento axiomático".

Para Santos Filho (2005), embasado no materialismo histórico dialético de Karl Marx, "O turismo, em sua concepção histórica, se constitui em um elemento que surge desde o aparecimento da mercadoria, quando o trabalho aparece como necessidade individual e não mais coletiva." (Santos Filho, 2005, p. 31). Seus estudos apontam para a percepção da influência do capitalismo nas práticas humanas e nelas também está o turismo.

Já segundo Panosso Netto (2011, p. 177), "o turismo deve ser analisado como fenômeno complexo de relações objetivas e intersubjetivas, calcado no significado que o 'partir' em viagem representa para cada turista". Com uma outra leitura do turismo, de base psicossocioantropológica, Perazzolo, Santos e Pereira (2013) enfatizam a necessidade de considerar o humano como elemento central na compreensão do fenômeno. Na proposta teórica das autoras (2013, p.141-142, tradução nossa), que busca seu fundamento no conceito de pulsão epistemofílica de Freud (1926), o fazer turismo é motivado "pelo impulso por conhecimento/experiências na sua forma mais primária". Essa pulsão, ou impulso por conhecer, experimentar, aprender, deriva de experiências que compõem o processo de constituição do sujeito como sujeito social. Sob essa perspectiva, a motivação para a busca de outro lugar, do novo que não encontra na 
origem, estaria ligada a essa pulsão, minimizando-se assim efeitos de ações persuasivas de vendas e de marketing, ou de modismos e estratégias econômico-comerciais.

Um lugar particular é preciso dar à definição da Organização Mundial do Turismo - OMT, a qual requer que seja analisada considerando que se trata de um organismo intergovernamental encarregado pela Organização das Nações Unidas de promover e desenvolver o turismo. Conforme Packman (2014), são fins da OMT a produção e a padronização de estatísticas, uniformizando critérios entre os diferentes países.

No que tange especificamente à dimensão pedagógica, recorre-se à proposta analítica, desenvolvida por Becker (2001) em seu texto "Modelos pedagógicos e modelos epistemológicos", deles pontuando apenas o que denomina "pedagogia diretiva e seu pressuposto empirista" e o que denomina "pedagogia relacional e seu pressuposto construtivista" - proposta à qual se agregam alguns outros olhares analíticos.

Ao estabelecer uma associação entre o que denominou de "pedagogia diretiva" e empirismo, Becker (2001, p. 17) caracterizou um processo de ensino-aprendizagem fortemente influenciado pela concepção segundo a qual a gênese do conhecimento vem do meio físico e social. O professor passa a assumir-se como representante do meio social (objeto), que determina o aluno (sujeito), este, tábula rasa, não apenas em seu nascimento, mas também diante dos conteúdos escolares. O professor torna-se a principal fonte de informação, cabendo-Ihe nela "escrever" esses conteúdos. O professor ensina, o aluno aprende, acentuando-se assim a dicotomia entre sujeito e objeto. O sujeito aluno não tem assim papel significante na elaboração e no desenvolvimento do conhecimento. $\mathrm{O}$ empirismo se institui como fundamento do paradigma newtoniano-cartesiano, característico da "ciência moderna", como a define Köche (2015), em que as teorias são tidas como descrições fiéis do real, exatas, objetivas, comprovadas pela experimentação resultante da observação científica e destituídas da subjetividade de quem a produz. Santos (2007, p. 91) menciona que, desde a institucionalização da escola ocidental como lugar da educação formal, o ensinar se configura como modo de propiciar ao aluno aceder ao conhecimento científico, verdadeiro. O aluno "deve adquirir esse conhecimento "relevante" - cuja relevância, institucionalizada, está no fato de ser considerado científico".

Uma prática pedagógica no modelo diretivo, tal como abordado, aponta para processos avaliativos voltados à exatidão da reprodução do conteúdo comunicado em sala de aula. Nesses "pressupostos" está presente a concepção de avaliação como medida, a qual, segundo Fernandes (2005), configura um procedimento técnico que, por meio de testes bem construídos, busca medir com rigor e isenção as aprendizagens dos alunos, tendo como foco unicamente os conhecimentos e como principais funções: classificar, selecionar, certificar. Descontextualizada, referida a uma norma padrão (média, por exemplo), com comparação entre alunos, privilegia a quantificação dos resultados em busca da objetividade, procurando assegurar a "neutralidade" do avaliador.

Em oposição ao modelo da pedagogia diretiva com seus pressupostos empiristas, tem-se o modelo pedagógico relacional que se origina do Construtivismo, concepção que tem por base a Epistemologia Genética de Jean Piaget, a qual é "naturalista sem ser positivista, que coloca em evidência a atividade do sujeito sem ser idealista, que se apoia igualmente no objeto ao mesmo tempo que o considera um limite e que, sobretudo, vê no conhecimento 
uma construção contínua" (Piaget, 1983, p. 5). Para ele, conhecer é transformar o objeto (assimilação) e transformar a si próprio (acomodação), ambos, sujeito e objeto, sendo projetos a ser construídos, ambos não tendo existência a priori, constituindo-se mutuamente na interação, independentemente de o homem trazer, desde o nascimento, uma bagagem hereditária que remonta a milhões de anos de evolução e de o meio social sintetizar milhares de anos de civilização.

Em sua proposição de como se dá a gênese psicológica do ser humano, ou de como se dá a construção da inteligência pela criança e pelo adolescente, Piaget (1983) caracterizou a inteligência como estrutura e função: a primeira, vinculada ao suposto de que está presente uma organização, envolvendo processos crescentemente complexos, derivando na reorganização contínua da inteligência; a segunda, associada à compreensão de que a inteligência visa sempre à adaptação do sujeito a seu meio. Nesse sentido, referindo-se ao conhecimento como produto da interação, Misukami (1986, p. 60) acrescenta que "O indivíduo é considerado como um sistema aberto, em reestruturações sucessivas em busca de um estágio final nunca alcançado por completo".

Outra contribuição importante é trazida por Vygotsky (1984), cuja proposição teórica sociointeracionista assemelha-se à de Piaget no que tange ao suposto da construção do objeto (realidade) pela sua interação com ele e consequente reorganização interna. O estudioso russo, por sua vez, atribui papel essencial à linguagem nos processos de aprendizagem, ou seja, nos processos de interação com o meio físico e humano, e como fator essencial para ocorrer o entrecruzamento entre pensamento e linguagem, os quais deixam de ser processos distintos. Segundo essa proposição teórica, a linguagem, construída inicialmente por meio de processos marcadamente culturais e intersubjetivos, só mais tarde assume um caráter intrassubjetivo.

Trazendo a esse contexto o processo avaliativo, Misukami (1986, p.83) ressalta que "Uma das formas de verificar o rendimento é através de reproduções livres, com expressões próprias, relacionamentos, [...] explicações práticas, explicações causais, etc.". As considerações da autora reportam à avaliação denominada por Fernandes (2005, p. 65) de "avaliação formativa alternativa" (AFA). Processo de referência cognitivista e construtivista e que assume princípios da Psicologia Social, das teorias socioculturais e sociocognitivas, a AFA está prioritariamente a serviço do desenvolvimento das aprendizagens e não de classificações em escalas, requerendo para tal a utilização predominante de métodos qualitativos. Trata-se de uma avaliação para a aprendizagem e não da aprendizagem, voltada a que os alunos aprendam melhor, com compreensão, utilizando e desenvolvendo suas competências, nomeadamente as do domínio cognitivo e metacognitivo. Diversamente da avaliação somativa, não integrada na aprendizagem, que se volta à identificação da consecução de objetivos gerais, utilizando os mesmos critérios para todos, a AFA é contínua, interativa, relativa a todo tipo de objetivos de aprendizagem, voltada para reorientar, melhorar ou apoiar. 


\section{EXAME NACIONAL DE DESEMPENHO DOS ESTUDANTES - ENADE E SUA APLICAÇÃO AOS CURSOS DE GRADUAÇÃO EM TURISMO}

$\mathrm{Na}$ medida em que esta investigação aborda, pela ótica de coordenadores, contribuições do Enade para a melhoria dos cursos de graduação em Turismo, torna-se pertinente aqui ressaltar objetivos e objeto das provas aplicadas aos estudantes de Turismo referidos nos documentos legais do INEP. Para isso, será utilizado o Relatório-Síntese de 2012, o último a que se tinha acesso quando da elaboração da pesquisa.

Assim, tomando por referência a prova realizada no mesmo ano, esta se pautou pela Portaria INEP $n^{\circ}$ 40, que estabeleceu as diretrizes para a avaliação do componente de formação geral, e pela Portaria INEP n⿳丷. 217, que estabeleceu as diretrizes para a avaliação do componente específico da área do Turismo, ambas datadas de 22 de junho de 2012.

\section{QUESTÕES SOBRE FORMAÇÃO GERAL}

No tocante ao componente de formação geral, a Portaria INEP 40 menciona o foco que será dado nas questões à formação de um profissional ético e comprometido com a sociedade em que vive e que revele compreensão de temas não restritos àqueles de sua área específica de formação.

\section{QUESTÕES SOBRE CONHECIMENTO ESPECÍFICO DA ÁREA DE TURISMO}

Em 2012, a avaliação relativa a esse componente, segundo o Art. $4^{\circ}$ da Portaria n. 217, teve como objetivos: I. avaliar o desempenho dos estudantes em relação às competências adquiridas e desenvolvidas ao longo de sua formação, a saber: habilidades, conhecimentos gerais e conteúdos profissionais específicos, visão crítica e reflexiva contextualizada; II. socializar os resultados da avaliação em relação às competências necessárias ao bacharel em Turismo, buscando criar uma cultura de comprometimento e autoavaliação pessoal e profissional; III. apresentar um panorama comparativo que permita a compreensão do contexto, necessidades e potencialidades dos cursos de graduação na área do Turismo.

O Exame, que possui duração de 4 (quatro) horas, compreende 40 questões, sendo 10 da parte de formação geral (8 de múltipla escolha e 2 discursivas $=25 \%$ da prova) e 30 da parte de formação específica (27 de múltipla escolha e 3 discursivas $=75 \%$ ). As questões de conhecimento geral são comuns a todas as áreas.

\section{CAMINHOS METODOLÓGICOS TRILHADOS}

A pesquisa realizada, definindo-se como qualitativa e de caráter exploratório, objetiva analisar, numa abordagem hermenêutica, processos de mudança e qualificação de projetos pedagógicos e de práticas pedagógicas e avaliativas resultantes particularmente de estudo analítico-interpretativo da prova do Enade para os cursos de graduação em Turismo, conduzido por coordenações de curso. Optou-se, como recorte temporal, pela prova de 
2012 (não se dispunha ainda dos resultados de 2015); como recorte espacial, por cursos de graduação oferecidos no Rio Grande do Sul, estado em que se encontram cursos consolidados (um dos quais em universidade que abriga um Programa de Mestrado e Doutorado), ao que se somou a característica de serem oferecidos por instituições que recobrem as diferentes naturezas jurídicas: federal, comunitária, confessional e privada. Observou-se ainda o fato de terem participado do Enade em suas edições de 2006, 2009 e 2012 (três deles iniciaram na década de 1990), critério entendido como um elemento a mais, denotador de consolidação na oferta desses cursos. Tinha-se como pressuposto metodológico que, por se tratar de pesquisa qualitativa e, como tal, sem pretensões de generalizações indutivas, os resultados depreendidos seriam compreendidos não como dados comprobatórios, mas como sinalizadores do processo analítico efetivado pelos sujeitos da investigação.

Foram realizadas entrevistas semiestruturadas, as quais versaram sobre quatro eixos: (I) organização do processo operacional de análise, (II) concepções de turismo subjacentes às questões, (III) avaliação das questões de cunho geral e (IV) concepções pedagógicas e metodológicas igualmente subjacentes às questões. Corresponderam a cada um deles, respectivamente, as seguintes questões orientadoras: Operacionalmente como a coordenação do curso se organiza para o processo de análise da prova do Enade? Quais as instâncias envolvidas? (Eixo 1) Como o curso avalia o enfoque dado na prova em relação às questões de cunho geral? (Eixo 2) Referentemente à parte específica sobre a área do Turismo, como o curso avalia o enfoque dado nas provas com relação a formulações conceituais de turismo? (Eixo 3) A seu ver, que concepções de ordem pedagógica e metodológica estariam subjacentes às questões formuladas e que pressupostamente estariam sendo efetivadas nas práticas pedagógicas cotidianas? (Eixo IV).

Como representativos dos cursos selecionados, constituíram-se sujeitos da pesquisa os respectivos coordenadores (SC), uma vez que, por força das suas funções, competiria a eles conduzir as atividades de avaliação da prova do Enade. Cabe observar, porém, que nem todos os coordenadores que se enquadravam dentro dos critérios previstos concordaram em participar da pesquisa. Tem-se assim o seguinte quadro, considerados aqueles que concederam entrevista: (SC1) - atualmente é professor do curso, sendo coordenador à época da prova e em período posterior; (SC2) - coordenador, tanto no momento presente quanto à época de realização da prova; (SC3) - mesma situação que o SC2. Conta-se também com a entrevista de outro coordenador (SC4), o qual é atualmente coordenador e, à época da prova, era professor do curso. Suas respostas, no entanto, foram consideradas complementares, quando essas trouxerem alguns elementos/aspectos que eventualmente pudessem contribuir para a reflexão. Ocorre que algumas informações prestadas diziam respeito a procedimentos institucionais que abrangem outros cursos, ou ainda ao que sucedeu a prova de 2009 e antecedeu a de 2012, envolvendo diretamente os professores. Segundo foi mencionado por ele, o curso deixaria de ser bacharelado e estava sendo direcionado para ser ofertado como curso de Tecnologia. Uma vez que os cursos de formação de tecnólogos não são submetidos ao Enade, os resultados do exame perderam em importância: estavam em fase de mudança o quadro de professores, currículo, metodologia, por exemplo. Essa mesma situação acabou por interferir nos registros de memória sobre a própria prova de 2012, de forma que se coloca uma situação diferente com relação aos sujeitos coordenadores 1, 2 e 3. 
Uma vez transcritas as entrevistas de cada sujeito atinentes a cada um dos eixos orientadores, agruparam-se as respostas de todos os sujeitos relativas a cada um dos eixos, com vistas a elaborar, quando pertinente, quadros descritivos e analíticos, em que se demarcaram os termos-chave (unidades ideativas) afetos à questão orientadora. Nesse agrupamento, algumas vezes, deslocaram-se alguns fragmentos presentes em respostas relativas a outro eixo, mas que diziam respeito ao eixo em análise. O número de sujeitos (quatro) facilitou o trânsito analítico entre as respectivas respostas. A esse processo sucedeu, para cada um dos eixos, uma síntese dos procedimentos analíticos, evidenciando-se elementos comuns, dissemelhanças e aspectos específicos de destaque.

A síntese interpretativa final, na sequência à análise das respostas, pautou-se pelo disposto nos documentos do Enade 2012, bem como pelos pressupostos teóricos relativos às formulações conceituais do Turismo e a concepções pedagógicas e de avaliação.

\section{A VOZ DOS COORDENADORES}

Os dados advindos da análise das respostas são a seguir sinteticamente apresentados.

\section{EIXO I - ORGANIZAÇÃO DO PROCESSO OPERACIONAL DE ANÁLISE}

Esse processo analítico conduziu primeiramente à elaboração, para cada sujeito, de quadro organizado em três palavras-chave: Instâncias institucionais envolvidas; Processo de análise da prova e do relatório; Medidas decorrentes, compreendendo aquelas envolvendo alunos e outras envolvendo os professores.

Sob essa perspectiva, fala comum dos coordenadores versa sobre ações no sentido de informar aos alunos a importância do Enade do ponto de vista individual e institucional. Identifica-se o envolvimento das instâncias educacionais para análise da prova e/ou seus relatórios. Exceção feita ao SC1, os demais entrevistados mencionaram o envolvimento da Coordenação em conjunto com o corpo docente do curso, e/ou Núcleo Docente Estruturante (NDE) e/ou Colegiado. As instâncias administrativas superiores têm o papel de informar aos coordenadores quais cursos participarão do Enade. Quanto às ações empreendidas, o que mais chama a atenção, no entanto, é a menção, por três dos SCs, à inserção do modelo de questão do Enade nas avaliações institucionais, visando à melhoria nos resultados do exame - o que se expressa, a título de exemplo, em verbalizações como: "Então, nosso plano de ação foi inserir o modelo de questão do Enade em todas as disciplinas específicas" (SC2); "nós temos 70 disciplinas no curso, todas as disciplinas oferecem 25\% da sua avaliação em formato Enade" (SC3). A análise desse procedimento operacional será retomada quando do exame de respostas referentes ao Eixo IV.

\section{EIXO II - CONCEPÇÕES DE TURISMO SUBJACENTES ÀS QUESTÕES}

Considerando a percepção de formulações conceituais sobre turismo subjacentes à prova, as referências dos respondentes se mantêm no nível genérico, o que denotam respostas 
como: "se poderia agudizar algumas questões ali teóricas, questões de teoria do Turismo" (SC2); "se consegue perceber que quem está preparando a prova está tendo cuidado de sim, de entender um pouco mais daquilo que tá na vanguarda dos conceitos do Turismo" (SC3); "não tanto a questão teórico-conceitual, mas os assuntos. Se tem Copa do Mundo, se tem Olimpíadas, por exemplo" (SC2).

Outra percepção das concepções do Turismo presentes nas questões da prova é a que faz alusão à tendência para as questões mercadológicas: "a prova assim ela tinha uma tendência, as questões tinham uma prevalência de questões mais relacionadas com o mercado, com aspectos relacionados ao mercado, mais quantitativas" (SC1). Nessa mesma direção, outro coordenador considera que a prova, no que tange a formulações conceituais de turismo com foco diferente do mercadológico, tem muito a avançar. Refere-se também à ênfase dada à segmentação turística, parecendo haver uma tentativa de aproximação com documentos do Ministério, como a questão da regionalização.

Ora, se observadas as questões da prova específicas à área, elas repousam prioritariamente no sistemismo, na forma como o concretiza o Sistema de Turismo (Sistur), de Beni (2008) - aliás, teórico citado na questão de número 11 - e seus respectivos componentes (os conjuntos das Relações Ambientais, da Organização Estrutural e das Ações Operacionais, abrangendo diferentes subsistemas como o ecológico, o econômico, o social-cultural, da superestrutura, da infraestrutura, do mercado, da oferta, da demanda, de produção, de distribuição e de consumo). Do conjunto de questões, 9, ou 31,0\% com relação ao total de questões específicas ao Turismo, envolvem planejamento; 11, ou 37\%, a gestão. Adjetivados por "público(a)" (10 incidências, ou 34,4\%), encontram-se elementos como poder, organização, entidades, gestão, planejamento, setor, política e o próprio termo "sistema". Explicitamente, porém, do ponto de vista teórico, não há qualquer menção, nas entrevistas, ao sistemismo, tampouco contraposições a outras concepções teóricas dentre aquelas anteriormente sintetizadas.

\section{EIXO III - AVALIAÇÃO DAS QUESTÕES DE CUNHO GERAL}

No que diz respeito às questões de cunho geral, estas são avaliadas positivamente por dois dos coordenadores, pelo entendimento de que a formação do profissional em Turismo não pode restringir-se à dimensão técnica: "é fundamental para o mercado profissional, e no Turismo, é fundamental que a gente tenha, sim, o aluno que não seja deslocado do seu mundo" (SC3). O SC2 assinala ainda a relevância de o exame atentar para questões atuais como uma forma para que melhor possa ser percebida a importância de um profissional atualizado, não apenas no que diz respeito ao Turismo, mas também no que tange à influência que pode exercer na sociedade e, por consequência, direta ou indiretamente, no próprio turismo. Contudo, aspectos relativos à formulação das questões ou do peso que lhes é dado são mencionados como variáveis a serem revistas: "E isso foi o que os professores dessas disciplinas apontaram, foi quase unânime. No entendimento deles, a formulação das questões" (SC2). Esse aspecto, aliás, já havia sido apontado na resposta relativa ao Eixo 1. 


\section{EIXO IV - CONCEPÇÕES PEDAGÓGICAS E METODOLÓGICAS SUBJACENTES ÀS QUESTÕES}

A questão norteadora relativa ao Eixo IV convergia para três pontos, os quais se constituíram em palavras-chave para a elaboração de quadro-síntese das respostas: proposições teórico-conceituais de ordem pedagógica e metodológica (que estariam subjacentes à prova); repercussões na avaliação do desempenho dos alunos; reavaliação do Projeto Pedagógico do Curso e consequentes repercussões sobre práticas pedagógicas cotidianas.

Como já ocorrera com relação aos conceitos de Turismo, não foram explicitadas concepções pedagógicas e/ou metodológicas remetendo ao âmbito teórico-conceitual. As respostas recaem sobre ações empreendidas na elaboração dos instrumentos de avaliação de desempenho, tais como a introdução de questões que exijam maior criticidade e posicionamento ("As questões discursivas que eu lembro, assim, sempre tinha, por exemplo, a citação, a redação sobre a situação e também que eu lembro, tinha, que o aluno se posicionasse, de que forma resolver aquele problema ou de que forma seria uma questão, uma situação ideal ou próximo do ideal." (SC1)), ou, ainda, questões no modelo Enade ("[...] o curso tomou uma série de medidas que visaram qualificar o aluno para o exame com um processo a médio prazo [...]". Foi acordado com o corpo docente e com o NDE a obrigatoriedade de todas as disciplinas do curso oferecerem $25 \%$ de sua avaliação no modelo do Enade. [...] O projeto pedagógico do curso se refez na medida em que a gente precisou inserir a obrigatoriedade na avaliação das questões no formato Enade" (SC3)).

Quanto às práticas cotidianas (que, em princípio, são pautadas pelo quadro teóricoconceitual pedagógico-metodológico), somente SC2 as menciona, destacando a ênfase dada por professores aos conteúdos da prova e, ao mesmo tempo, a "cobrança" de reflexão pelo aluno acerca desses conteúdos, associada à dimensão prática - o que é proposto, a título de exemplo, em projetos de estágio e de eventos.

Referentemente a possíveis reavaliações do projeto pedagógico do curso resultantes da análise da prova e dos resultados obtidos, somente dois sujeitos coordenadores manifestaramse sobre isso. O primeiro (SC2) referiu que as análises incidiram sobre ementas e conteúdos de disciplinas e também sobre competências necessárias à resolução das questões (com destaque às que levaram a um maior número de erros). Pelo fato de as referidas competências, segundo ele, serem contempladas no projeto pedagógico, entendeu-se que não eram necessárias alterações: Observe-se que se trata do mesmo sujeito que apontou algumas repercussões na prática pedagógica cotidiana. Já, segundo explicação de SC3, a mudança restringiu-se à oficialização da obrigatoriedade de inserção nas avaliações de questões "tipo Enade", num percentual de $25 \%$.

\section{PROPONDO UMA SÍNTESE INTERPRETATIVA}

Encaminhar uma síntese interpretativa requer primeiramente reportar-se à questão de pesquisa e particularmente a alguns dos aspectos teóricos tomados como de referência. 
Perguntou-se como estaria se configurando, sob a condução dos sujeitos coordenadores de cursos respondentes, o processo analítico das questões e dos relatórios de provas do Enade e as respectivas repercussões nos projetos pedagógicos e nas práticas pedagógicas e avaliativas.

Tem-se presente que se trata de uma avaliação somativa externa, logo, como ressaltado anteriormente, trata-se, em princípio, de uma avaliação que, ligada à sua natureza de instrumento nacional, busca "medir" as aprendizagens dos alunos, tomando os resultados como indicativos da qualidade dos cursos, permitindo que estes se vejam no conjunto dos cursos no estado, na região ou no país (Fernandes, 2005).

De outra parte, entretanto, é oportuno observar que o Enade dá a conhecer previamente o que será objeto de avaliação em termos de competências e conteúdos (gerais e específicos à área), considerando o pressuposto de que devam ter sido desenvolvidos ao longo do processo formativo - afinal, trata-se de avaliação de final de curso. Isso se faz mais contundente, quando as competências e os conteúdos indicados são aproximados ao que propõem as Diretrizes Curriculares Nacionais para os cursos de graduação em Turismo no que tange ao perfil de egresso conjugado com as competências ali enunciadas (Resolução CNE/CES N. 13, de 24 de novembro de 2006, Art. 4ロ). Isso considerado, outra dimensão da prova precisa ser destacada, quando se volta a análise às questões formuladas, cuja solução requer do aluno o domínio de conceitos e de processos cognitivos a eles associados, em sua grande parte, em níveis reflexivos que demandam operações mentais superiores, como: identificação, caracterização, análise, interpretação, compreensão, articulação, planejamento, organização, controle, avaliação, apropriação, utilização de técnicas de pesquisa, geração, promoção, implantação. São operações referidas na Portaria N. 217/2012 - Artigo 4ロ, as quais, se presume, estejam sendo desenvolvidas pelo estudante, constituindo-se em objetivos de ensino e de aprendizagem ao longo do curso. Estão aí em jogo duas dimensões do conhecimento: como processo e como conteúdo assimilado.

Reporte-se aqui à caracterização da inteligência como estrutura, anteriormente mencionada, a qual Piaget (1983) vincula ao suposto de que está presente uma organização, envolvendo processos crescentemente complexos, derivando na reorganização contínua da inteligência, ou, ainda, à referência que faz Misukami (1986) ao indivíduo considerado como um sistema aberto, o que implica reestruturações sucessivas na direção de um estágio final que jamais será completamente alcançado. A título de ilustração, veja-se a seguinte questão extraída da prova original. 
Figura 1: Questão 31 da Prova Enade 2012

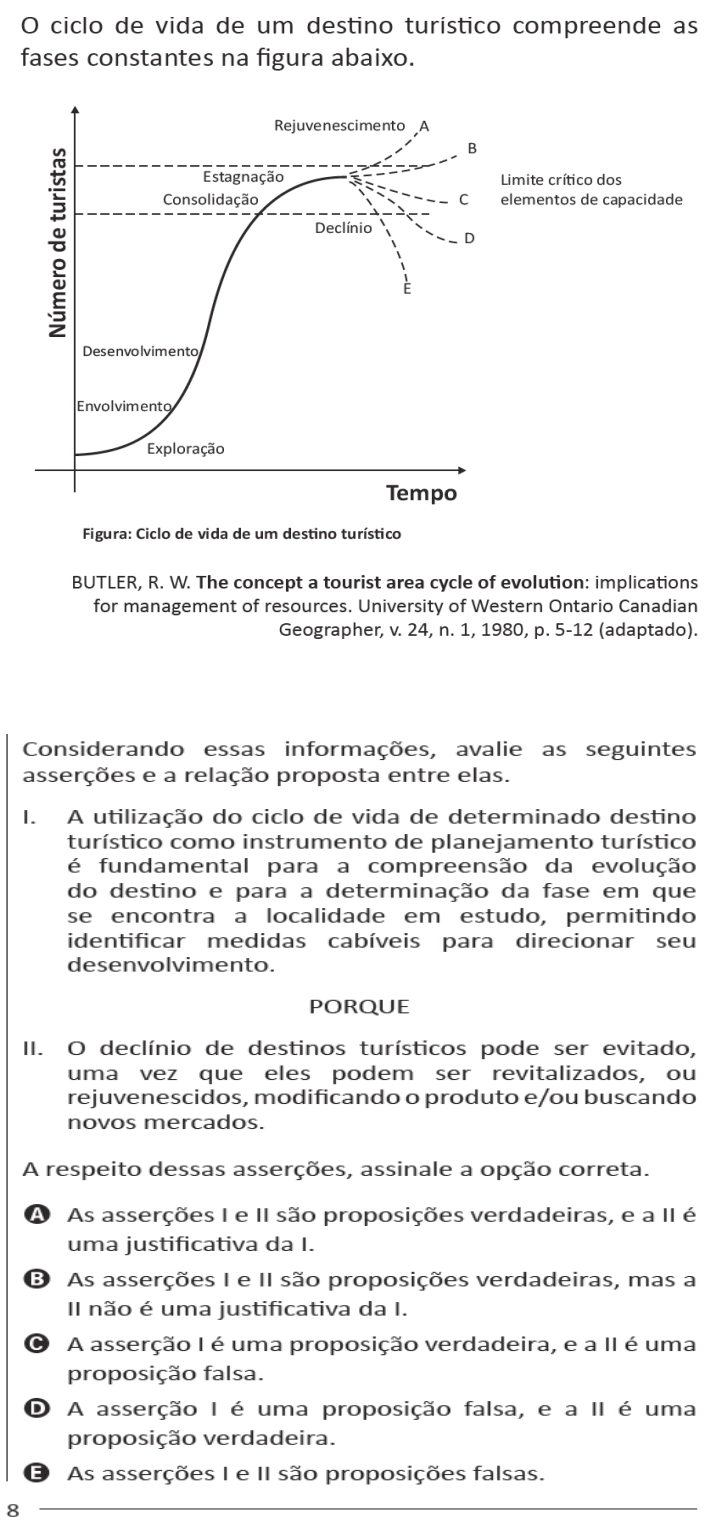

Fonte: Enade 2012

Essa questão, conforme Relatório Enade, foi considerada difícil pelos alunos e apresentou um índice fraco de discriminação. Com o concurso de uma análise linguísticotextual, trazendo à superfície conectores que aí estariam subjacentes, pode-se depreender que a questão demanda para sua resolução:

A) interpretação do diagrama, que põe em relação o número de turistas e as fases do ciclo de vida [tempo] do destino turístico, as quais apresentam uma trajetória de exploração, envolvimento, desenvolvimento, consolidação e estagnação (estas duas últimas configurando a faixa do declínio ou do limite crítico de elementos de capacidade), apontando para a possibilidade de uma nova fase ascendente: a do rejuvenescimento; 
B) a discriminação e a relação das informações centrais da assertiva I: ciclo de vida do destino turístico = instrumento de planejamento turístico PORQUE permite compreender a evolução do destino no tempo [COMO?], determinando a fase em que a localidade em estudo se encontra [as fases estão indicadas no diagrama] e, CONSEQUENTEMENTE, permitindo identificar medidas cabíveis PARA direcionar seu desenvolvimento [evitando o declínio ou buscando o rejuvenescimento];

C) a discriminação e a relação das informações centrais da assertiva II: relação de CAUSA da qual o impedimento do declínio do destino é o EFEITO (possibilidade de revitalização ou rejuvenescimento, conforme apontado no diagrama, acima da faixa do declínio), efeito este possível POR MEIO de modificação do produto ou busca de novos mercados [atraindo novos turistas].

D) estabelecimento de uma relação lógico-explicativa ou não entre (c) e (b), ambas corretas, considerando (a): ao contrário, (c) tem, na origem, as informações explicativas de (b).

Retomando a taxonomia revisada de Bloom (Anderson L. Krathwohl, 2001; Ferraz e Belhot, 2010), que propõe uma combinação dos tipos de conhecimento a serem desenvolvidos e os processos mentais utilizados para a aquisição desses conhecimentos, a resolução da questão implica análise, ou divisão da informação em partes relevantes e entendimento da relação existente entre as partes, como também avaliação, ou seja, julgamento mediante um critério estabelecido, no caso, qualitativo). A resposta correta para a questão é a alternativa "b".

No que tange às questões de formação geral, estão presentes processos cognitivos semelhantes aos das questões específicas à área do Turismo, ao que se acresce, em conformidade com o art. $3^{\circ}$ da Portaria 217, o domínio de conhecimentos que "evidenciem a compreensão de temas que transcendam ao seu ambiente próprio de formação e sejam importantes para a realidade contemporânea" (Brasil, 2012, p.1).

Há que se ressaltar ainda que a prova compreende, tanto no que se reporta à formação geral quanto à formação específica, questões dissertativas, as quais, para além dos conceitos e das situações enunciadas, exigem do aluno competência de textualização argumentativa com as particularidades do texto escrito, compreendendo "clareza, coerência, coesão, estratégias argumentativas, utilização de vocabulário adequado e correção gramatical do texto" (Portaria 217, art. $3^{\circ}$, parágrafo $5^{\circ}$ ). Mais uma vez, trata-se de competência textual a ser desenvolvida durante todo o processo de formação do aluno, não se restringindo a situações pontuais como as de aplicação de provas, ao que tudo indica, somativas, ainda que com feedback do professor.

Um exemplo elucidativo pode ser encontrado na questão discursiva 1. 


\title{
TURISM曲
}

Figura 2.

\section{QUESTÃO DISCURSIVA 1}

As vendas de automóveis de passeio e de veículos comerciais leves alcançaram 340706 unidades em junho de 2012 , alta de $18,75 \%$, em relação a junho de 2011 , e de $24,18 \%$, em relação a maio de 2012 , segundo informou, nesta terça-feira, a Federação Nacional de Distribuição de Veículos Automotores (Fenabrave). Segundo a entidade, este é o melhor mês de junho da história do setor automobilístico.

Disponivel em: ehttp://br.financas.yahoo.comx. Acesso em: 3 jul. 2012 (adaptado)

Na capital paulista, o trânsito lento se estendeu por $295 \mathrm{~km}$ às $19 \mathrm{~h}$ e superou a marca de $293 \mathrm{~km}$, registrada no dia 10 de junho de 2009. Na cidade de São Paulo, registrou-se, na tarde desta sexta-feira, o maior congestionamento da história, segundo a Companhia de Engenharia de Tráfego (CET). Às $19 \mathrm{~h}$, eram $295 \mathrm{~km}$ de trânsito lento nas vias monitoradas pela empresa. O índice superou o registrado no dia 10 de junho de 2009, quando a CET anotou, às 19 h, $293 \mathrm{~km}$ de congestionamento.

\author{
Disponivel em: shttp://noticias.terra.com.brs. Acesso em: 03 jul. 2012 (adaptado).
}

J governo brasileiro, diante da crise econômica mundial, decidiu estimular a venda de automóveis e, para tal, reduziu o imposto sobre produtos industrializados (IPI). Há, no entanto, paralelamente a essa decisão, a preocupação constante com o desenvolvimento sustentável, por meio do qual se busca a promoção de crescimento econômico capaz de incorporar as dimensöes socioambientais.

Considerando que os textos acima têm caráter unicamente motivador, redija um texto dissertativo sobre sistema de transporte urbano sustentável, contemplando os seguintes aspectos:

a) conceito de desenvolvimento sustentável; (valor: 3,0 pontos)

b) conflito entre o estímulo à compra de veículos automotores e a promoção da sustentabilidade; (valor: 4,0 pontos)

c) ações de fomento ao transporte urbano sustentável no Brasil. (valor: 3,0 pontos)

Fonte: Enade 2012

Em documento publicado pelo INEP, são apresentados os padrões de resposta:

Figura 3: Padrão de resposta da Prova Enade 2012

\begin{abstract}
Padrão de Resposta
O estudante deve redigir texto dissertativo, abordando os seguintes tópicos:

A - A ideia de que desenvolvimento sustentável pode ser entendido como proposta ou processo que atende às necessidades das gerações presentes sem comprometer capacidade similar das gerações futuras.

B - A redução do IPI para a compra de automóveis incentiva a utilização de veículos movidos a combustíveis fósseis num cenário de baixa mobilidade urbana nas cidades brasileiras. Mais automóveis nas cidades gera mobilidade deficitária e mais consumo de combustiveis fósseis, pois os motores ficam mais tempo acionados. O aumento da queima de combustiveis nestes motores gera maiores quantidades de emissões de gases poluentes, como os gases de efeito estufa, o monóxido de carbono, os óxidos de enxofre e os particulados. Como consequência, ar atmosférico das cidades se torna mais poluído.

C-São ações de fomento:

Concessão de subsídios governamentais ao transporte coletivo em detrimento do transporte particular, como exemplo a redução de IPI para a fabricação de equipamentos de transporte coletivo como ônibus, vagões de metrôs, trólebus e barcas públicas.

Concessão de subsídios governamentais para a manufatura e venda de veículos de transporte movidos a combustíveis limpos ou mais sustentáveis, como os veículos a energia solar, gás natural, energia elétrica, hidrogênio, biodiesel, dentre outros.

Incentivo ao uso de bicicletas e da caminhada, como a construção de ciclovias e de passeios seguros, amplos e agradáveis.
\end{abstract}

Fonte: Inep

Esse conjunto de elementos relativos às características conceituais, cognitivas e redacionais até aqui assinalados remetem a concepções e procedimentos não condizentes com o modelo diretivo de base empirista. Os objetivos estabelecidos nas Portarias 40 e 217 (coerentes com as DCN's para os cursos de graduação em Turismo) apontam, ao contrário, para a pertinência dos modelos pedagógicos relacional de base construtivista, em que sujeito e objeto são projetos a ser construídos, constituindo-se mutuamente na interação (Piaget, 2003), ou sociointeracionista, segundo escopo teórico vigotskyano, o que pressupõe a respectiva observância cotidiana na prática pedagógica, com a mediação do professor.

Tem-se na dinâmica da capacidade de pensar movimentos que se dão por meio de processos mentais crescentes, intermináveis e espiralizados (Perazzolo, Pereira e Santos, 
2011). E, nesse quadro, ganha relevância a substituição do ensino dos fatos pelo ensino das relações, assim como, numa perspectiva sociointeracionista, a mediação na direção do conhecimento, mediação marcada pela presença do outro e do próprio ambiente. Como esse outro, no âmbito da educação formal, estaria o professor, mediador, portanto, no processo de favorecimento à realização de aprendizagens, ao desenvolvimento das funções mentais superiores. E nessa dinâmica relacional, quando mediada e levada à prática cotidiana, professor e aluno aprendem e se transformam: com o auxílio de situações-problema propostas ao aluno (como força desequilibrante), este é estimulado, como o fazem os pesquisadores, a buscar novas estratégias de compreensão da realidade e, em seus processos de assimilação e acomodação, a buscar soluções para as situações que lhe forem apresentadas (Piaget, 2003).

Entende-se que um indicativo do que os cursos de graduação em Turismo avaliados pelo Enade poderiam depreender da prova é a importância dessa dinâmica cotidiana na direção de desenvolvimento de conhecimentos e processos cognitivos crescentes, a qual tenderá a repercutir positivamente na instrumentalização do aluno para a realização da prova do Enade, requerendo, como atividade inicial fundamental, um exame minucioso dos conhecimentos focalizados nas questões e das competências/habilidades (processos cognitivos) subjacentes a elas. Nas questões, tal qual referido anteriormente, encontram-se situações-problema expressas em gráficos, dados contextuais gerais ou relacionados à área do turismo envolvendo aspectos sociais, culturais, econômicos, mercadológicos, gestão pública e privada, tecnologias, entre outros, os quais, direta ou indiretamente, disciplinar, interdisciplinar ou transversalmente, dizem respeito às concepções pedagógicas e metodológicas que estariam previstas no projeto pedagógico do curso e, consequentemente, às atividades pedagógicas promovidas pelos docentes.

Identifica-se um "espaço vazio" entre a Prova Enade 2012 e demais avaliações pontuais ("Da prova para provas") a que fazem alusão os coordenadores, denotando um percurso contrário às proposições de Fernandes (2005), ao abordar a avaliação formativa (a avaliação para a aprendizagem) pautada pela busca da compreensão, mediante utilização e desenvolvimento de competências, particularmente as do domínio cognitivo e metacognitivo. Não se obteve maior detalhamento sobre o "preenchimento" desses espaços com práticas cotidianas pedagógicas relacionais, tendo por foco, de modo especial, dinâmicas para o desenvolvimento de processos cognitivos que viessem a ser depreendidos da análise da prova. Identificam-se alguns sinalizadores nessa direção, como antes referido. De forma geral, obtiveram-se menções pontuais que, em sua maior parte, destacaram aspectos julgados importantes para a formação do aluno e que estavam sendo contemplados na prova.

Sem que se esteja pondo em xeque a pertinência de avaliações pontuais somativas, o que se mostra importante sublinhar é o fato de que essas poderiam estar dando lugar a avaliações formativas no caso de desenvolvimento de um trabalho cotidiano de base construtivista ou sociointeracionista, favorecedor do desenvolvimento da capacidade de pensar, do desenvolvimento das funções mentais superiores, muitas delas requeridas para responder às questões da prova. Esse seria mais um elemento pedagógico e metodológico a ser depreendido pelos cursos no exame detalhado das questões da prova do Enade, no caso, da Prova 2012. 
No que tange ainda à repercussão das análises em modificações dos projetos pedagógicos, recuperando respostas dos entrevistados, essa se concretizou no exame de competências requeridas para a resolução de questões confrontadas com as elencadas no projeto (SC2) e na normatização da inserção de questões modelo Enade nas avaliações (SC3). Não foram explicitados processos/atividades de revisão de partes estruturais como Referenciais teóricos, Concepção metodológica e de avaliação, por exemplo.

\section{NA DIREÇÃO DE CONSIDERAÇÕES FINAIS}

O percurso investigativo até aqui realizado permite afirmar que importantes elementos/aspectos pontuais, tanto pedagógicos e metodológicos, quanto os vinculados a formulações conceituais de turismo, são depreendidos pelos cursos na análise da prova Enade 2012, independentemente do tratamento quantitativo que a prova possa dar aos resultados. No entanto, tendo em conta o exame das questões e das entrevistas aqui desenvolvido, entende-se que haveria outros sinalizadores de natureza conceitual, processual e operacional a depreender no âmbito das práticas pedagógicas ou da área do Turismo além dos que se identificaram, os quais viriam a potencializar esse papel positivo - que não deixa de ser atribuído à prova pelos sujeitos coordenadores.

Ressalte-se que avaliações pontuais somativas e avaliações processuais formativas não se excluem, podendo retroalimentar-se. Aí está presente o desafio, destacado por Nóvoa (2005), da utilização necessariamente cuidadosa e inteligente, por avaliadores e avaliados, dos instrumentos e dos resultados aferidos das avaliações externas, para o que se faz necessário o respaldo do pensamento e o acompanhamento científicos, perspectiva essa na qual este trabalho pretende se enquadrar.

Vale relembrar, nessa direção, duas leituras simultaneamente possíveis dos resultados dessa prova do Enade. De um lado, ressaltam-se os quantitativos, pretensamente publicizados como forma de accountability à sociedade e que têm sido geradores de ranqueamento de cursos e instituições, reportando ao projeto educacional finalista, funcionalista, instrumental de curso e de universidade como provedora de forças profissionais. De outro, a prova também oferece "pistas" aos cursos para que, em vez de serem pensadas estratégias defensivas ou justificadoras, que seja favorecida a conduta reflexiva, como também fomentado o desenvolvimento da atitude científica. Essas "pistas" tornam-se explícitas naquelas questões que têm por objeto o próprio processo de pesquisar (Questões 14 e 15).

Mais ainda. Quando o foco se dirige ao desenvolvimento de operações cognitivas superiores, evidencia-se a necessidade de que os cursos assumam a importância de buscar esse desenvolvimento no cotidiano da sala de aula. Para isso, faz-se indispensável que os docentes possam inteirar-se de teorias pedagógicas, de modo especial, de princípios do construtivismo e do sociointeracionismo e, assim, possam promover situações de ensino nas quais a aprendizagem seja significativa para o aluno, ao se ver, por exemplo, inserido no mundo do trabalho. Várias questões são ilustrativas disso (Questões 10, 13, 23, por exemplo). Por outro lado, essas mesmas características levam a pôr em questão a longa extensão da prova para um período de quatro horas, o que poderia acabar por repercutir na sua resolução pelos alunos e, consequentemente, em seus resultados. 
Não se poderia deixar de aqui destacar que nenhum dos coordenadores tem formação superior em Licenciatura. Suas respostas, além de permitirem depreender seu comprometimento com a qualidade das atividades de ensino e aprendizagem, trazem reflexos, em diferentes graus, de aprendizagens decorrentes de sua experiência docente e/ ou de atualizações posteriores - o que dá um significado especial àquilo que vem sendo por eles realizado juntamente com os professores. Nesse contexto de possíveis aprendizagens institucionais, se ou quando compartilhado o reconhecimento da importância e da aplicabilidade destas ponderações, a análise da prova mostra como ideal um trabalho multidisciplinar integrando diferentes instâncias acadêmicas e administrativas (gestores, coordenadores, professores) - o que, pelo que se depreende de parte de relatos dos coordenadores, ainda não se efetiva satisfatoriamente.

Outros destaques merecem ainda particular atenção. Apesar dos cuidados metodológicos que balizaram todo o desenvolvimento da pesquisa, a partir dos quais se chegaram às formulações analítico-interpretativas apresentadas, há um ponto a sublinhar: o tempo transcorrido entre a entrevista e os processos que teriam ocorrido na análise da prova 2012. Expressões, como "pelo que me lembro", "não lembro exatamente", ou "não lembro", se mesclam nas falas dos entrevistados - o que pode ser entendido como ecos dessa defasagem temporal. Também não fica excluída a possibilidade de repercussões mais ou menos positivas nos registros da memória, na dependência de o processo de análise da prova ter sido regularmente realizado ou não desde a primeira participação no exame. A isso vêm somar-se possíveis reflexos de alterações quer de coordenador, quer de foco no processo caso do SC4 que, após a realização da prova de 2012, teve sua atenção voltada à implantação de um novo tipo de curso de graduação. Não é possível detectar o grau de influência dessas variáveis na formulação das respostas e, consequentemente, nas correspondentes análises, porém não se pode deixar de tê-las em conta.

Finalmente, tem-se igual clareza da possibilidade/necessidade de serem realizados outros percursos de pesquisa, como redimensionando objeto e objetivos deste estudo para uma abordagem longitudinal da prova Enade para os cursos de graduação em Turismo, abrangendo as edições de 2006, 2009, 2012 e também a de 2015; ou, ainda, ampliando a geografia de escuta de coordenadores, professores e alunos, associando técnicas qualitativas a quantitativas na obtenção e na análise dos resultados.

\section{REFERÊNCIAS BIBLIOGRÁFICAS}

Anderson, L. W.; Krathwohl, K. R. A. (2001) Taxonomy for learning, teaching and assessing: a revision of Bloom's taxonomy or educational objectives. New York: Longman.

Becker, F \& Marques, T. (2007). Ser professor é ser pesquisador. Porto Alegre, Mediação.

Beni, M.C. (c2008). Análise estrutural do turismo. (13ed.). São Paulo: Senac.

BRASIL. Lei no 10.861, de 14 de abril de 2004. Institui O Sistema Nacional de Avaliação da Educação Superior - Sinaes e dá outras providências. Brasília, DF. Recuperado de: http://www.planalto. gov.br/ccivil_03/_ato2004-2006/2004/lei/l10.861.htm.

BRASIL. Portaria № 217, de 10 de junho de 2012. Instituto Nacional de Estudos de e pesquisas Educacionais Anísio Teixeira. Diário Oficial da União. Recuperado de: http://download.inep. gov.br/educacao_superior/enade/legislacao/2012/portarias_diretrizes_enade_2012.pdf. 
BRASIL. Portaria № 40, de 25 de junho de 2011. Instituto Nacional de Estudos de e pesquisas Educacionais Anísio Teixeira. Diário Oficial da União. Recuperado de: http://download.inep. gov.br/educacao_superior/enade/legislacao/2012/portarias_diretrizes_enade_2012.pdf.

Fernandes, D. (2005). Avaliação das aprendizagens: desafios às teorias, práticas e políticas. Lisboa: Texto editores.

Ferraz, A.C.M \& Belhot, R.V. (2010). Taxionomia de Bloom: revisão teórica e apresentação das adequações do instrumento para definição de objetivos instrucionais. Gestão de Produção, 2(17), 421-431.

Gastal, S.A \& Moesch, M. (2007). Turismo, políticas públicas e cidadania. São Paulo: Aleph.

Goergen, P. (1997). A avaliação universitária na perspectiva da pós-modernidade. Avaliação: revista da avaliação da educação superior, 2(3), 53-65.

Köche, J.C. (2013). Fundamentos de metodologia científica: teoria da ciência e iniciação à pesquisa. (32ed.). Petrópolis: Vozes.

Krippendorf, J. (2003). Sociologia do turismo: para uma nova compreensão do lazer e das viagens. (3ed.). São Paulo: Aleph.

Mizukami, M.G.N. (1986). Ensino: as abordagens do processo. São Paulo: EPU.

Moesch, M. (2000). A produção do saber Turístico. São Paulo: Contexto.

Moesch, M. (2013). O lugar da experiência e da razão na origem do conhecimento do turismo. Revista Cenário, 1(1), 8-28. Recuperado 4nov,2016,de: http://seer.bce.unb.br/index.php/revistacenario/ article/view/9898/7245.

Nóvoa, A. (2005). Prefácio. In: Fernandes, D. Avaliação das aprendizagens: desafios às teorias, práticas e políticas (pp.11-13). Lisboa: Texto Editores.

Packman, E. T. (2014). Sobre as definições de turismo da OMT: contribuições à história do pensamento turístico. Anptur - Ceará. Recuperado, 20, jun, 2017, de: <http://www.anptur.org. br/novo_portal/anais_anptur/anais_2014/arquivos/DFP/DFP1/034.pdf.

Panosso netto, A \& Nechar, M.C. (2016). Turismo: perspectiva crítica - textos reunidos. São Paulo: Assis: Triunfal, Gráfica e Editora.

Panosso Netto, A. (2011). Filosofia do turismo: teoria e epistemologia. São Paulo: Aleph.

Perazzolo, O.A, Pereira, S \& Santos, M.M.C. (2013). Dimensión Relacional de la Acogida. Estudios y Perspectivas en Turismo, 22(1), 138-153. Recuperado 14 set,2017, de http://www. estudiosenturismo.com.ar/PDF/V22/N01/v22n1a08.doc.pdf

Piaget, J (2002). Epistemologia genética. (2ed.). São Paulo: M Fontes.

REIS, F. G. (2011). Processos de avaliação e de acreditação do ensino superior no Brasil. Política educacional interventista, papel do mercado e alternativas a partir da comparação com outros países In: SIMÕES, Sonia Colombo et al. desafios da gestão universitária contemporânea. Porto Alegre: Artmed, p.246-269.

Reis, F.G. (2011). Processos de avaliação e de acreditação do ensino superior no Brasil Política educacional interventista, papel do mercado e alternativas a partir da comparação com outros países. In Simões, S.C \& Et al (Eds), Desafios da gestão universitária contemporânea (pp. 246269). Porto Alegre: Artmed.

Santos filho, J (2005). Ontologia do turismo: estudo de suas causas primeiras. Caxias do Sul, RS: EDUCS.

Santos, M.M.C. 2008. Prática Docente na Formação do Turismólogo. Revista Brasileira de Pesquisa em Turismo. 1(1), 84-109. Recuperado 25jul,2016, de: https://www.rbtur.org.br/rbtur

SANTOS, M. M. C; PERAZZOLO,O. A;PEREIRA, S. (2009). Dimensões Relacionais ePsicopedagógicas da Hospitalidade - Projeto de pesquisa. Universidade de Caxias do Sul.

Vigotsky, L.S (1998). Pensamento e linguagem. (2ed.). São Paulo: M Fontes. 
Rev.Tur., Visão e Ação, v21, n2, p68-81, Mai./Ago. 2019 - Balneário Camboriú, Santa Catarina, Brasil

CONTRIBUIÇÃO DE CADA AUTORA:

THAYS DE OLIVEIRA MARCELINO: desenvolvimento da pesquisa e elaboração textual MARCIA MARIA CAPPELLANO DOS SANTOS: orientação da pesquisa e elaboração textual

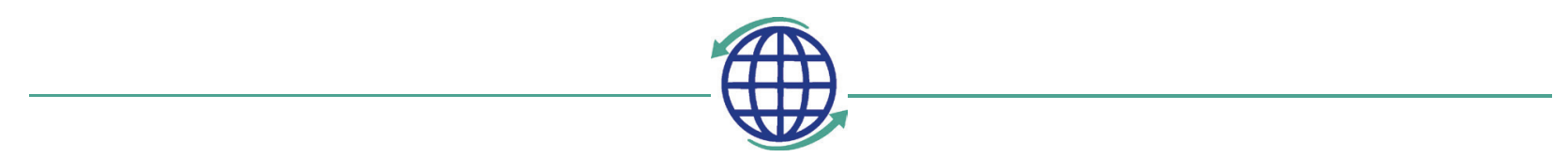

